\title{
Normas para la detección de faringitis estreptocóccica con alta especificidad pero baja sensibilidad
}

Rimoin AW, et al. Arch Dis Child. 2005;90(10):1066-70.

\section{Objetivo}

Valorar prospectivamente el desempeño de las normas de decisión clínica de la Organización Mundial de la Salud (OMS) para la faringitis estreptocóccica en países en vías de desarrollo.

\section{Diseño}

Validación prospectiva de una regla de predicción clínica. ${ }^{*}$

\section{Lugar}

Tres clínicas en Río de Janeiro (Brasil), Cairo (Egipto) y Zagreb (Croacia)

\section{Pacientes}

Participaron 1810 niños de dos a 12 años que consultaron consecutivamente desde $9 / 2001$ a $8 / 2003$ por odinofagia. Se excluyeron a aquellos que presentaban al menos uno de los siguientes: uso de antibióticos orales o intramusculares en los últimos tres ó 28 días previos a la consulta respectivamente, historia de fiebre 0 carditis reumática o enfermedades concomitantes que requirieran hospitalización.

\section{Medición de resultados principales}

Las normas de la OMS establecen que debe sospecharse la presencia de faringitis por estreptococo B-hemolítico del grupo $A$ (SBHGA) y realizar el tratamiento empírico de la misma en todo niño menor de cinco años que presente exudado faríngeo y ganglios cervicales con evidencias de inflamación. Se realizó el exámen clínico de todos los niños por médicos entrenados para dicho fin. Las muestras fueron procesadas en los laboratorios de cada centro, cuyo personal fue capacitado según lo establecido por la OMS, considerándose al cultivo como test diagnóstico de referencia de faringitis estreptocóccica.

\section{Resultados principales}

La tabla 1 describe las características de los pacientes enrolados.
Tabla 1: Características de los pacientes por centro

\begin{tabular}{c|c|c|c}
$\begin{array}{c}\text { Nímero de pacientes } \\
\text { por país }\end{array}$ & $\begin{array}{c}\text { Edad Media } \\
\text { (DE) }\end{array}$ & $\begin{array}{c}\text { Múmero menor a } \\
\text { cinco anos y \% }\end{array}$ & $\begin{array}{c}\text { Gultivo positivo } \\
\text { a sBirta }\end{array}$ \\
\hline Brasil (191) & 5,5 años $(0,2)$ & $81(42,4 \%)$ & $24,6 \%$ \\
\hline Croacia (200) & 6,4 años $(0,1)$ & $64(32 \%)$ & $42 \%$ \\
\hline Egipto (1419) & 4,9 años $(0,1)$ & $749(52,8 \%)$ & $27,7 \%$ \\
\hline
\end{tabular}

DE: desvío estándar.

En los niños menores de cinco años, la sensibilidad de las normas de la OMS en el diagnóstico de faringitis por SBHGA fue baja en los tres países. No obstante, la especificidad fue uniformemente alta para ambos grupos de edad (Tabla 2) no hallándose diferencias estadísticamente significativas entre grupos.

Tabla 2: Características operativas de las normas OMS por edad y centro

\begin{tabular}{|c|c|c|c|c|c|}
\hline Edad & País ("ni") & $\begin{array}{c}\text { Sensibilidad } \\
\text { ([C95\%) }\end{array}$ & $\begin{array}{l}\text { Especififididad } \\
\text { ([695\%) }\end{array}$ & $\begin{array}{l}\text { VPP } \\
\text { (1695\%) }\end{array}$ & $\begin{array}{l}\text { VPN } \\
\text { (1G95\%) }\end{array}$ \\
\hline \multirow[t]{3}{*}{ Dos a 12 años } & Brasil (191) & $8,5(2,4-20,4)$ & $95,8(91,2-98,5)$ & $45,5(12,2-73,8)$ & $76,7(69,4-82,2)$ \\
\hline & Croacia (200) & $5,9(1,9-13,4)$ & $93,9(93,9-97,9)$ & $41,7(15,2-72,3)$ & $57,9(50,6-65,1)$ \\
\hline & Egipto (1419) & $4,1(2,4-6,6)$ & $97(95,7-97,9)$ & $34,0(20,9-49,3)$ & $72,9(70,5-75,3)$ \\
\hline \multirow[t]{3}{*}{ Menor a cinco años } & Brasil (81) & $0,0(0,0-030,9)$ & $95,7(88,1-99,1)$ & $0,0(0,0-70,7)$ & $87,2(77,7-93,7)$ \\
\hline & Croacia (64) & $3,6(0,1-18,4)$ & $94,4(81,3-99,3)$ & $33,3(0,8-90,6)$ & $55,7(42,568,5)$ \\
\hline & Egipto (749) & $4,6(1,9-8,8)$ & $96,7(94,9-98,0)$ & $29,6(13,8-50,2)$ & $76,9(73,6-79,9)$ \\
\hline
\end{tabular}

VPP: Valor Predictivo Positivo, VPN: Valor Predictivo Negativo

\section{Conclusiones}

Las actuales normas de la OMS para la detección de faringitis estreptocóccica presentan alta especificidad pero escasa sensibilidad, lo que conduce a que no sean tratados hasta $96 \%$ de los niños con cultivo positivo para SBHGA. Por lo tanto no son ideales para los países en vías de desarrollo que presenten alta incidencia de enfermedad reumática.

Fuente de financiamiento: USAID y en Croacia por el departamento de salud y desarrollo de la niñez y adolescencia, OMS

\section{Comentario}

La faringitis aguda motiva diariamente numerosas consultas pediátricas y si bien el mayor porcentaje de las mismas es de causa viral, el SBHGA es la causa bacteriana más frecuentemente halla$\mathrm{da}^{1}$. La incidencia de fiebre Reumática y la prevalencia de cardiopatía reumática (ambas complicaciones no supurativas de la faringitis por SBHGA mal o no tratada) son un verdadero problema en países en vías de desarrollo.

Se han realizado numerosos sistemas de puntuación basados en datos clínicos y epidemiológicos con el objeto de predecir la probabilidad de que una faringitis aguda sea producida por SBHGA, con resultados variables. Por otro lado se observo que el uso selectivo de estudios diagnósticos para SBHGA no solo aumenta la proporción de resultados positivos, sino también el porcentaje de estudios con resultados positivos realmente infectados ${ }^{2}$ (no meramente portadores).

La faringitis aguda por SBHGA presenta determinadas características clínicas y epidemiológicas que ayudan a su diagnostico: ocurre entre los entre cinco y los 15 años de edad y habitualmente durante el invierno y principios de la primavera. El cuadro clínico es de comienzo agudo, con odinofagia y fiebre. Suele haber edema amigdalino y faríngeo, con o sin placas exudativas, y adenome- galias dolorosas laterocervicales. Otros hallazgos son el enrojecimiento y el edema de la úvula, petequias en el paladar, excoriaciones nasales y erupción escarlatiniforme ${ }^{3}$. Sin embargo, la signosintomatología de las faringitis estreptocóccicas y las virales se superponen tan estrechamente, que establecer un correcto diagnostico, aún para el clínico más avezado, puede ser un verdadero desafío. Por ello, la Academia Americana de Pediatría ${ }^{4}$ establece aún la necesidad de confirmación microbiológica (método rápido de diagnóstico y/o cultivo en caso de ser negativo el primero) en todo niño con faringitis aguda, si bien refiere que no hay que olvidar las características clínico epidemiológicas de la enfermedad al tomar la decisión de obtener las muestras.

\section{Conclusiones del comentador}

En países en vías de desarrollo con alta incidencia de fiebre y carditis reumática, las normas de la OMS no parecen ser lo suficientemente sensibles como para ser de utilidad en la práctica diaria. Se necesitará mejorar la sensibilidad de las reglas para poder aplicarlas en los ámbitos estudiados.

Erica Rodriguez Gesto [ Médica Pediatra. Consultorios Externos Hospital de Niños Ricardo Gutiérrez. ]

* ver glosario Rodriguez Gesto E. Las normas de la OMS para la detección de faringitis estreptocóccica presentan alta especificidad pero escasa sensibilidad. Eviden. act. pract. ambul. 9(1):11. En-Febr.2006. Rimoin AW, Hamza HS, Vince A, Kumar R, Walker CF, Chitale RA, da Cunha AL, Qazi S, Steinhoff MC. Evaluation of the WHO clinical decision rule for streptococcal pharyngitis. Arch Dis Child. 2005;90(10):1066-70. PMID: 15941772.

\section{Referencias}

1. Bisno AL, Gerber MA. Practice guidelines for the diagnosis and management of group A streptococcal pharyngitis. Clin Infect Dis. 2002;35:113-125

2. Gerber MA, Shulman ST. Rapid diagnosis of Pharyngitis Caused by Group A Streptococci. Clin Microbiol Rev. 2004;17(3):571-80.

3. Gerber, MD. Diagnosis and Treatment of Pharyngitis in Children. Pediatr Clin N Am 2005:52:729-747.

4. American Academy of Pediatrics Committee on Infectious Diseases. Red Book: report of the Committee on Infectious Diseases. 26th edition. Elk Grove Village (IL): American Academy of Pediatrics; 2003. 